THE KURUME MEDICAL JOURNAL Vol. 9, No. 3, 1962

\title{
EXPERIMENTS ON THE SARTORIUS MUSCLE FIBERS DEPOLARIZED BY POTASSIUM RICH OR CALCIUM FREE MEDIUM
}

\author{
KENICHI NODA \\ Department of Physiology, Kurume University School of Medicine, \\ Kurume-shi, Japan \\ (Received for publication December 1, 1962)
}

\section{INTRODUCTION}

It is of great importance to clarify the genesis and the maintenance of the resting membrane potential of the cells in excitable tissue. Currently, it is believed that the major part of the resting potential is established by Donnan's equilibration of the potassium ions across the cell membrane because the change of the membrane potential of the cell is linearly proportional to the logarithm of the external potassium ion concentrations. Many reports indicate that the resting membrane potentials are explainable in terms of the concentration difference of potassium, chloride and sodium ions, and the membrane permeability to these ions.

However, some authors $(1,2,3,4,5)$ reject the ionic explanation for the origin of the membrane potential from the fact that there is no interrelationship between internal potassium concentration and the resting potential of frog muscle fibers or giant axons. Their results showed that a great reduction or increase in intracellular potassium did not alter the membrane potential. On the other hand, another author (6) claims that internal potassium is not independent from the membrane resting potential in the extent of the physiological external concentration of potassium ions.

Nevertheless, all authors have observed the dependency of the resting potential upon the external potassium concentration. This shows that the potassium ions have an important role in the production of the resting potential. So, it is not meaningless to examine the relationship between the behavior of the potassium ions and the membrane potential.

At the present time, it is not known what per cent of internal ions is free. It is said that about $90 \%$ of internal potassium and about half of internal sodium move freely; however, this is not accurately known at the present time.

The present author has attempted to discover the process underlying the establishment of the normal resting potential difference in frog sartorius muscles by simultaneously observing the potential and the behaviour of potassium ions.

Part of this experiment was done in the Department of Biophysics of the University of Maryland, U.S.A. 


\section{METHODS}

Sartcrius muscles obtained from frogs were used throughout the year. The muscles were taken with great care under the dissecting microscope. The muscles isolated were equilibrated for 15 minutes in the experimental solutions. The muscles which were arificially depolarized to some extent by different procedures were used, but good reversibility was required in all muscles used for the experiments.

Microelectrode technique was used for estimating the resting potential and for detecting the action potentials in muscle fibers. For getting the action potentials, two microelectrodes were inserted into one fiber as the stimulating and recording electrode. From the $i^{-} \mathrm{v}$ curves obtained in the same way, the effective resistance was measured. The value of the resting potential of a muscle is an average value of the potential of the ten fibers in the surface layer of the muscle.

The net flux of an ion was determined by the chemical analysis, and the influx and efflux, which are the number of ions moving in unit time across a unit area of the membrane, were determined with the aid of radioisotopes. The chemical analysis of sodium and potassium ions in the muscle has been made with use of the flame photometer. The muscles were used for this purpose at the end of each experiment. After the experiment, muscles were put into isotonic sucrose solution for 10 seconds in order to remove the extracellular ions. The extra water of the muscle surface was taken out by placing the muscles on wet filter paper, and the muscle ash was made in a furnace at $550^{\circ} \mathrm{C}$.

The concentration of potassium or sodium ions was expressed by the index of $\mathrm{mM} / \mathrm{kg}$ fiber water. Extracellular space was taken as $15 \%$ of the muscle weight. Considering this, the intrafiber water was taken as $70 \%$ of the muscle weight corrected for extracellular space.

For the measurement of the outflux of $\mathrm{K}^{42}$, the muscle was first put into the experimental solution containing $\mathrm{K}^{42} \mathrm{Cl}$, and then it was transferred successively to the nonradioactive test solutions of a definite volume with a definite interval. These washed-out solutions and the muscle ash were counted. For the comparison of the effect of procedures, the desaturation curve or the rate constant curve was drawn. The efflux was expressed in terms of the fraction of the total $\mathrm{K}$ which leaves from muscle per second.

A standard Ringer solution having the following composition was used: 112 $\mathrm{mM} \mathrm{NaCl}, 1.8 \mathrm{mM} \mathrm{CaCl}_{2}, 2.5 \mathrm{mM} \mathrm{KCl}$ and $2 \mathrm{mM} \mathrm{NaHCO}_{3}$. Room temperature was about $22^{\circ} \mathrm{C}$.

The loading time in radioactive solution should next be considered. It has been said that a muscle cell contains two compartments for the potassium ions: one is directly proportional to the external potassium and another is relatively independent of it. It is necessary to accumulate $\mathrm{K}^{42}$ inside the cells in order to see the outgoing unidirectional movement of $\mathrm{K}^{42}$. If these two compartments could be easily distinguished in the potassium efflux experiments, it would be very favourable for the explanation of the movement of the potassium ion in the muscle. Accordingly, experiments have been carried out in which the time of soaking of muscles in radioactive potassium-containing Ringer was set at either 2 or 24 hours. The efflux of potassium from these muscles was measured, but the results do not 
give clear experimental data for the loading time, the results ranging from 7.4 to $9.2 \mathrm{pmoles} / \mathrm{cm}^{2} \mathrm{sec}$. which are not indicative of the difference in loading time.

\section{RESULTS}

1. Ca free depolarization and high $\mathrm{K}$ depolarization in frog sartorius muscle:

In the normal state, the muscle membrane of the frog sartorius shows a resting membrane potential of approximately $90 \mathrm{mV}$. In order to clarify the mechanism underlying maintenance of this steady potential, it is reasonable and helpful to examine the property of the muscle fiber membrane during depolarization. This is possible by comparing the membrane properties of the muscle in the artificially depolarized state to those in the normal state.

It is well known that when the external $\mathrm{K}$ ion concentration in Ringer has been increased the membrane potential changes proportionally to $[\mathrm{K}]_{0}$. The amount of the change in the potential is about $58 \mathrm{mV}$ in a ten-fold change in $[\mathrm{K}] \mathrm{o}$. In the simple removal of $\mathrm{Ca}$ ions from the external medium ( $\mathrm{Ca}$ free Ringer), the membrane potential is about $60 \mathrm{mV}$. The complete removal of the external $\mathrm{Ca}$ ions with use of EDTA in Ringer results in a reduction to 25 or $30 \mathrm{mV}$ (Figure 1 , B); however, the addition of EDTA in sucrose or choline system does not cause such a large reduction in resting potential. The level of resting potential reduced in EDTA sucrose Ringer or choline Ringer is, in general, $75 \mathrm{mV}$. Owing to the presence or absence of sodium ions, there is a different appearance of $\mathrm{Ca}$ free effect. In other words, $\mathrm{Ca}$ free conditions containing the agents to make the membrane excitable such as sodium or hydrazinium (7) show a remarkable lowering of resting potential level, but $\mathrm{Ca}$ free conditions with agents to make the membrane inexcitable, such as sucrose or choline, do not cause a great change in the potential level (Figure 1, D). Moreover, when the preparation which was immersed in $\mathrm{Ca}$ free sucrose Ringer for about 3 hours was transferred into $\mathrm{Ca}$ free or Ca free EDTA Ringer the resting potential remaining at a high level, at once, began to decrease, suggesting the presence of two groups in Ca free effect.

I $i$ is of interest to note the difference in the time lapse of depolarization in $\mathrm{Ca}$ free Ringer and in high $[\mathrm{K}]_{0}$. As shown in Figure $1, \mathrm{~A}$, the difference in the onset of depolarization probably indicates the difference in the action of $\mathrm{Ca}$ ions and $\mathrm{K}$ ions on the membrane.

High external $\mathrm{Ca}$, heavy metal ions or cocain can prevent the $\mathrm{Ca}$ free or $\mathrm{K}$ rich depolarization, similarly. The action potentials in Ca free Ringer disappear at the critical level similar to that in Ringer (at -55 to $60 \mathrm{mV}$ ), and those in high $\mathrm{K}$ Ringer at about $8 \mathrm{mM}[\mathrm{K}]_{0}$. A slight time-dependency can be seen in the time lapse occuring in $\mathrm{Ca}$ free depolarization, but can not be seen in $\mathrm{K}$ rich depolarization. This is one of the most important differences between these two types of depolarization.

2. The effect of pure saline upon the muscle membrane potential:

In comparison with the time to accomplish the complete change in membrane potential, the high $\mathrm{K}$ condition requires only 15 minutes while $\mathrm{Ca}$ free condition requires about 60 minutes. Next, the pure saline solution, which contains only sodium chloride in isotonic situation, was used for the purpose of the simultaneous application of both the $\mathrm{K}$ free and $\mathrm{Ca}$ free condition. The bathing solution was 
FIGURE I, A
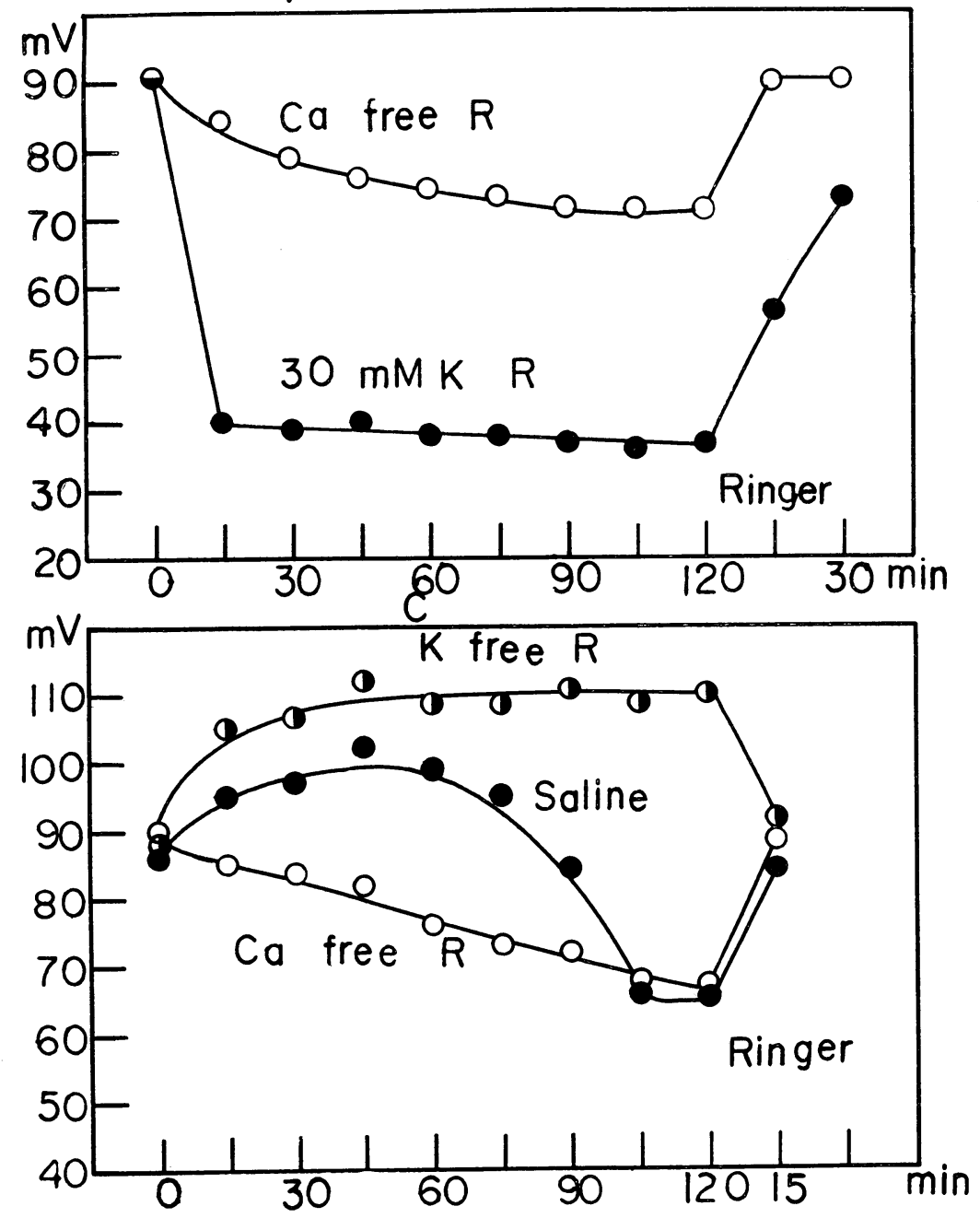

B

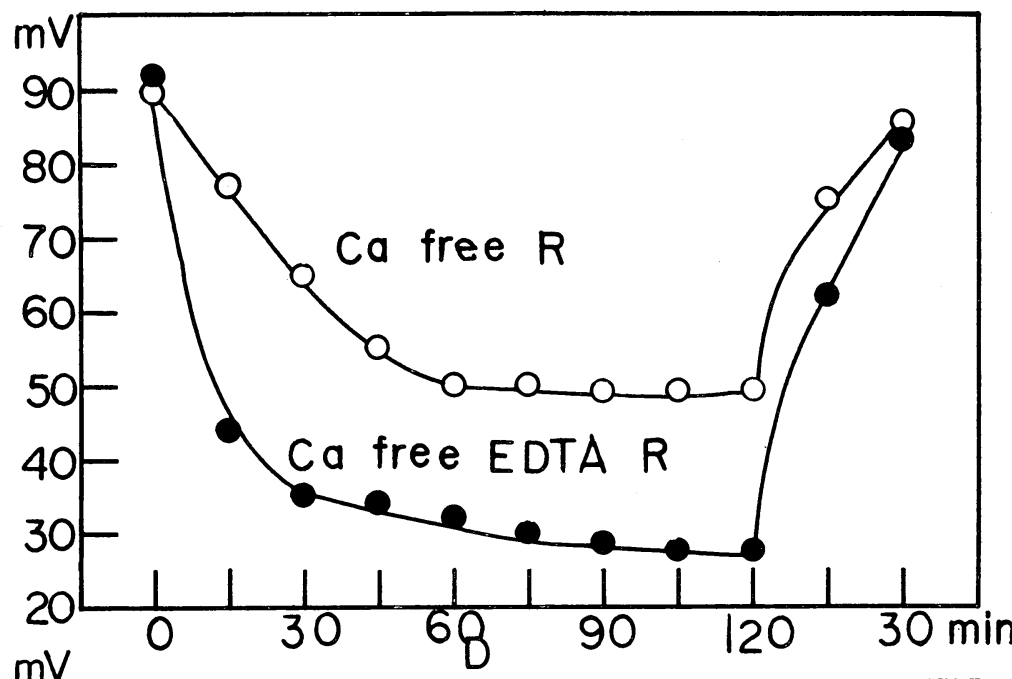

$\mathrm{mV}$

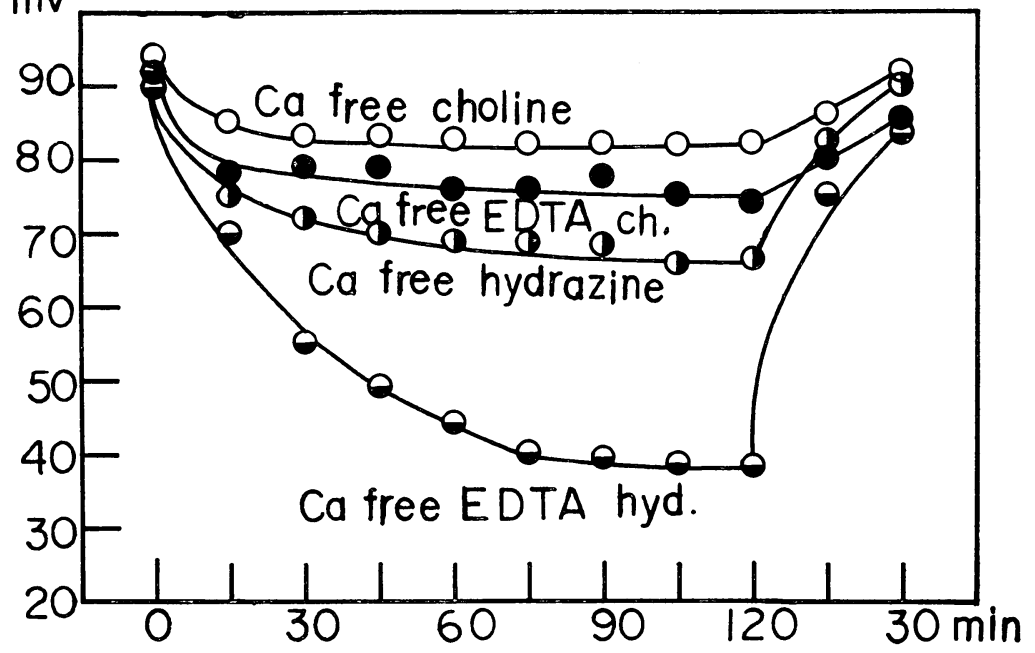

Figure 1. All curves show the temporal change of the resting potential of frog sartorius muscle in various solutions described in each Figure. In $A$, the difference in the time course of depolarization should be noted. In $C$, the curve in saline is interesting. All muscles show good reversibility. 


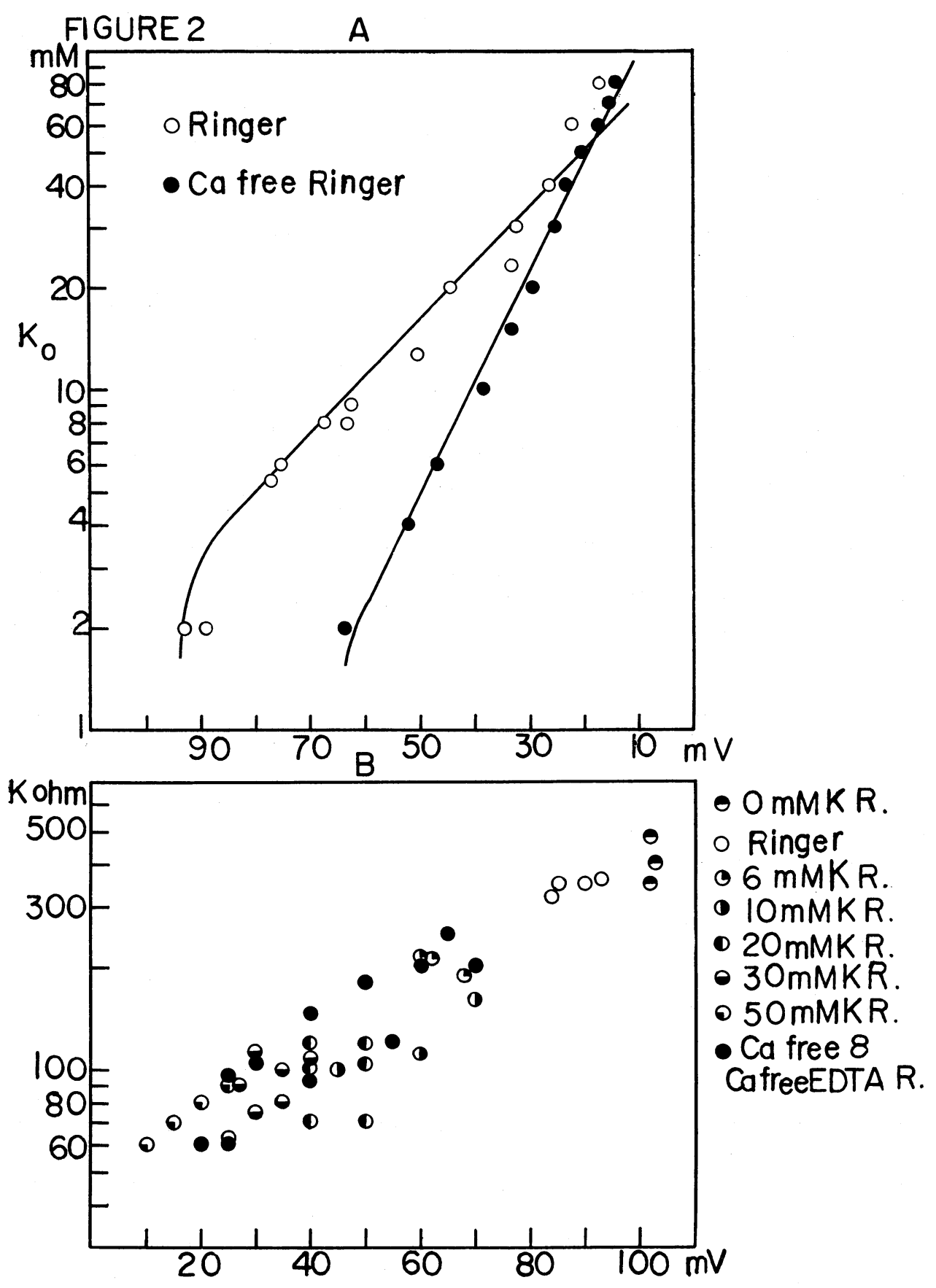

Figure 2. In $\mathrm{A}$, the sensitiveness of the resting potential to the external $\mathrm{K}$ concentration was measured in the muscles soaked in Ringer and $\mathrm{Ca}$ free Ringer. In $\mathrm{B}$, the effective membrane resistance $(\mathrm{K} \Omega$ ) was plotted against the various resting potential levels which were brought about by each condition described in the figure. 
frequently replaced. The effect of $\mathrm{Ca}$ removal did not contribute to the potential change initially. As seen in Figure 1, C, it can be said that the effect of external $\mathrm{K}$ ions is rapid and superficial, and that of $\mathrm{Ca}$ ions is slow but more essential. In the figure, we can understand the pure saline effect to be the simple algebraic sum of both effects during the first 40 minutes, and as only the $\mathrm{Ca}$ free effect in the later portion.

This result may indicate that the membrane sites which $\mathrm{K}$ ions or $\mathrm{Ca}$ ions affect are different, or that $\mathrm{K}$ ions and $\mathrm{Ca}$ ions can change the membrane property by different means.

3. External $\mathrm{K}$ concentration upon the membrane potential of the muscle depolarized by $\mathrm{Ca}$ free condition:

To compare the effect of $\mathrm{K}$ ions upon the membrane potential to that of $\mathrm{Ca}$ ions, the sensitiveness of the muscle membrane to external $\mathrm{K}$ ions has been investigated by the use of muscles which were previously depolarized in $\mathrm{Ca}$ free Ringer.

As is clear from the Figure 2, A, the membrane resting potential remaining in $\mathrm{Ca}$ free Ringer is still sensitive to the applied external high concentration of $\mathrm{K}$ ions. In the author's observation, the slope per ten-fold change in external $\mathrm{K}$ concentration was $56 \mathrm{mV}$ in Ringer and $30 \mathrm{mV}$ in $\mathrm{Ca}$ free Ringer.

From this, also, it can be said that the membrane site for $K$ effect and that for $\mathrm{Ca}$ effect should be different. In other words, it is supposed that $\mathrm{K}$ ions and $\mathrm{Ca}$ ions act independently to keep a certain level of the membrane potential.

4. Effective membrane resistance:

Besides the change in membrane potential, the change in effective membrane resistance was checked in $\mathrm{Ca}$ free or $\mathrm{K}$ rich media. The value of this resistance is the same regardless of the cause of the depolarization if the membrane depolarization is in the same degree. This relation can be seen in Figure 2, B. This probably suggests that the electrical properties of the membrane of the muscle which is depolarized by various procedures may be similar.

In $\mathrm{Ca}$ free and $\mathrm{K}$ rich media, the effective resistance which was measured at various levels of membrane potential changes respectively, but the replacement of sodium ions with sucrose or choline does not show such change in membrane resistance. Corresponding to the difficulty noted in the change of membrane potential in these media, the Ca free EDTA effect upon the membrane resistance is hardly seen in sucrose or choline Ringer. The external $\mathrm{Ca}$ or $\mathrm{K}$ itself may have some relation to the membrane resistance.

When the degree of the withdrawal of $\mathrm{Ca}$ or the addition of $\mathrm{K}$ was shown by the resting membrane potential level, the membrane resistance changed according to the change in the membrane potential, as shown in Figure 2, B.

Regardless of the cause by which the membrane potential is reduced, the value of effective resistance is in proportion to the value of the membrane potential. In other words, $\mathrm{Ca}$ free or $\mathrm{K}$ rich condition acts on the membrane properties via the common process which is considered to be the similar change in the membrane structure.

The tracer experiments similarly showed that $\mathrm{Ca}$ free or $\mathrm{K}$ rich condition accelerates the outflux of $\mathrm{K}$ continuously and also increases the outflux of membrane calcium transiently, as will be written later. Combining these results, it can be 
presumed that the withdrawal of membrane $\mathrm{Ca}$ may cause a reduction in membrane resistance or the lowering of membrane potential. But it must be known what the most fundamental or essential change is in the membrane in $\mathrm{Ca}$ free or $\mathrm{K}$ rich media.

5. Comparison of membrane depolarization and the efflux rate of the $\mathrm{K}$ ions:

The depolarization of the membrane potential of frog sartorius shows the same level in both $10 \mathrm{mM} \mathrm{K}$ Ringer and simple $\mathrm{Ca}$ free Ringer, the potential being around $60 \mathrm{mV}$. The $10 \mathrm{mM} \mathrm{K}$ Ringer was chosen to remove the mixture of the net gain of $\mathrm{K}$ in high $\mathrm{K}$. If depolarization can be caused by one mechanism, other phenomena in these muscles should be the same.

By chemical analysis after 24 hours soaking in each solution, the internal $\mathrm{K}$ and $\mathrm{Na}$ contents are around normal level in $10 \mathrm{mM} \mathrm{K}$ Ringer, however, $[\mathrm{K}]_{1}$ is reduced and $[\mathrm{Na}]_{\mathfrak{l}}$ is increased in $\mathrm{Ca}$ free Ringer.

In the same condition, $\mathrm{K}$ efflux increases about 2.1 times the normal rate in $10 \mathrm{mM} \mathrm{K}$ Ringer and 1.3 times in $\mathrm{Ca}$ free Ringer. This increase is a continuous change. These values have been obtained from the tracer experiments. The efflux of $\mathrm{K}$ has been expressed by the ratio of the rate of efflux of $\mathrm{K}^{42}$ to the total internal $\mathrm{K}$ concentration. This quantitative difference in $\mathrm{K}$ efflux may show the structural difference in the two media. Consequently, the influx of $\mathrm{K}$ ions may become larger in $10 \mathrm{mM} \mathrm{K}$ Ringer, but it may be at normal level in $\mathrm{Ca}$ free Ringer.

The increase of the efflux of $\mathrm{K}$ by $\mathrm{Ca}$ free depolarization in Ringer is similar to the value of $\mathrm{Ca}$ free depolarization in sucrose $\mathrm{SO}_{4}$ Ringer, and the rate of efflux increase by $10 \mathrm{mM} \mathrm{K}$ depolarization in Ringer has also been observed in $10 \mathrm{mM} \mathrm{K}$ sucrose $\mathrm{SO}_{4}$ Ringer to the same degree. This means that $\mathrm{K}$ efflux due to the membrane depolarization is independent from influences by the concomitant ions.

Moreover, $[\mathrm{K}]_{\mathbf{i}}$ in $\mathrm{Ca}$ free Ringer and in $\mathrm{Ca}$ free sucrose Ringer reduces similarly, however, $[\mathrm{Na}]_{1}$ in these solutions is various because of the difference in the external $\mathrm{Na}$ concentration.

This shows that the movements of $\mathrm{K}$ ions which are assumed to be the cause of the membrane potential may be different in these two conditions even in the same potential level.

TABLE 1

\begin{tabular}{|c|c|c|c|}
\hline & Ringer & Ca free Ringer & $10 \mathrm{mM} \mathrm{K}$ Ringer \\
\hline$[\mathrm{K}]_{\mathrm{i}}$ & $127 \mathrm{mM}$ & $106 \mathrm{mM}$ & $128 \mathrm{mM}$ \\
\hline$[\mathrm{Na}]_{\mathbf{i}}$ & $20 \mathrm{mM}$ & $46 \mathrm{mM}$ & $15 \mathrm{mM}$ \\
\hline $\begin{array}{l}\text { Ratio of increase } \\
\text { of } \mathrm{K} \text { efflux }\end{array}$ & 1 & 1.3 & 2.1 \\
\hline
\end{tabular}

Note: Each value is obtained by an average of 10 cases.

In both cases, the resting potential level of muscle fibers which have been depolarized is the same, however, the exchange process of $\mathrm{K}$ ions and the ionic 
distribution as its results are different from each other. These results show that the membrane potential level is not a direct reflection of $\mathrm{K}$ ion configuration across the membrane but the $\mathrm{K}$ ion distribution is probably a reflection of the membrane potential level. Moreover, Ca free depolarization and $10 \mathrm{mM} \mathrm{K}$ depolarization may have a respective change of the membrane property. From the simultaneous observation of the change of potential and $\mathrm{K}$ efflux, it can be said that the increase of $\mathrm{K}$ efflux in $\mathrm{K}$ rich solution is caused by the change of the membrane potential and its increase in $\mathrm{Ca}$ free solution is a result of the change of the membrane structure by which secondarily the membrane potential has been changed. The structural integrity for the normal operation of the membrane working may be less affected in $\mathrm{K}$ rich medium than in $\mathrm{Ca}$ free medium. It may be considered from these results that the resting potential is no longer so effective in altering the distribution of $\mathrm{K}$ ions in these conditions.

6. The restoration of excitability by anodal polarization:

In either $\mathrm{Ca}$ free EDTA Ringer or $30 \mathrm{mM} \mathrm{K}$ Ringer, the resting potential level reduces to about $40 \sim 25 \mathrm{mV}$, and this value of resting potential clearly gives no more action potentials. As reported previously (8), (9), the action potential can be obtained from muscles in $\mathrm{Ca}$ free or high $\mathrm{K}$ media by applying anodal polarization. This shows that the muscle is fully excitable in $\mathrm{Ca}$ free or $\mathrm{K}$ rich media. At this time, the threshold level for producing action potentials is fixed; i. e. the strength of the cathodal pulse of a definite duration should increase with the increasing of the anodal polarization. But the critical point is almost similar to that in Ringer.

After the appearance of the maximum action potential, the increase of anodal polarization does not affect the height of the action potential; e. g. $75 \mathrm{mV}$ in 112 $\mathrm{mM} \mathrm{Na}$ or $60 \mathrm{mV}$ in $30 \mathrm{mM} \mathrm{Na}$. This is not able to support the idea that the available sodium permeability is increased by anodal polarization (10).

In the well known sodium hypothesis on the excitation, the height of the action potential and the rate of rise are determined by $[\mathrm{Na}]_{0}$. In Ringer solution, the spike height is a linear function of the logarithm of $\mathrm{Na}$ concentration and is completely insensitive to the change in $[K]_{0}$. Strictly speaking, it has been said that the spike height corresponds to the Nernst diffusion potential calculated from the concentration of sodium ions on the two sides of the membrane. Now, the author has checked the action potential height in the muscles depolarized in $\mathrm{Ca}$ free or $\mathrm{K}$ rich medium.

In $\mathrm{Ca}$ free Ringer, the membrane potential reduces under the threshold level after spontaneous repetitive firing. At this level of the membrane potential we can not generate the action potential by the usual method. Likewise, the muscles soaked in high $\mathrm{K}$ exceeding about $8 \mathrm{mM}$ do not show action potential too. However, the author can get the action potential, strictly speaking, active depolarization, from the muscles in either of both media by applying the cathodal pulse during anodal hyperpolarization. This active depolarization is not in the all-ornone manner. But the shape and the progress are very similar to the natural action potential; i. e. they are both supposed to have the same ground for producing active depolarization. Accordingly, it seems to be reasonable to discuss these two processes from the same point of view. This active depolarization may give 


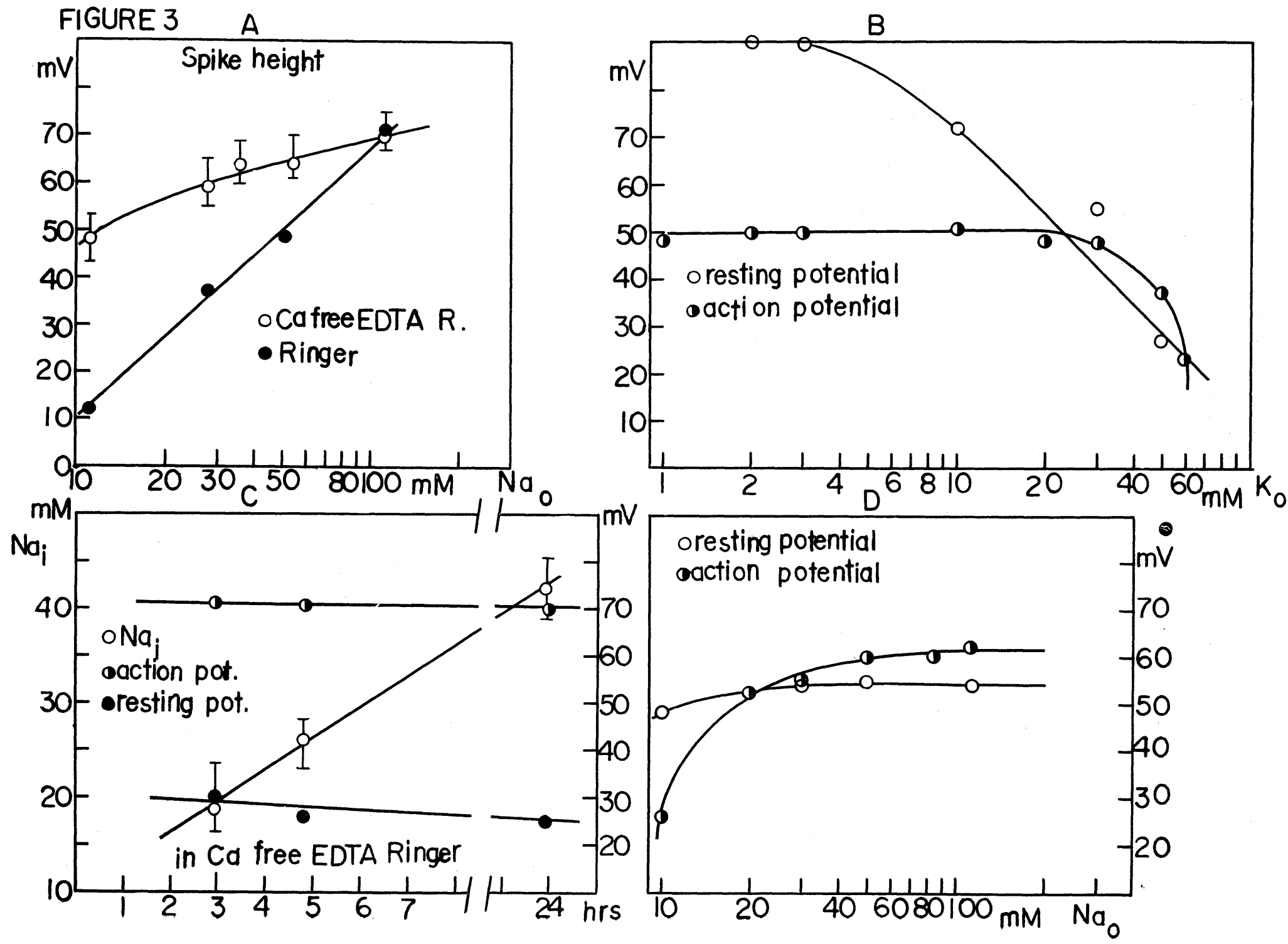

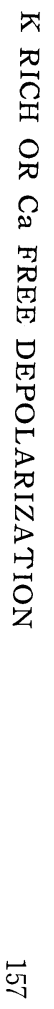


Figure 3. All figures show the height of the active depolarization produced in various conditions. A shows the change of spike height in $\mathrm{Ca}$ free EDTA Ringer in various concentrations of external $\mathrm{Na}$ ion. $\mathrm{B}$ is the action potential height in various external $\mathrm{K}$ concentrations in $50 \mathrm{mM}$ Na. C reveals the relation of spike in $\mathrm{Ca}$ free EDTA Ringer to the internal $\mathrm{Na}$ concentration. $\mathrm{D}$ is the shift of the active depolarization height in $20 \mathrm{mM} \mathrm{K}$ Ringer against the change of external Na concentration.

important information for understanding the generating process of the action potential. When the active depolarization in this anomalous condition is discussed the maximum spike height has been chosen.

A. Ca free depolarization and sodium ions:

The relationship between the height of action potentials thus produced and the external $\mathrm{Na}$ concentration has been examined. This relationship does not agree with that observed in Ringer. These results have led to the idea that the action potential height does not agree with the Nernst relation which shows that the spike height is determined by the concentration ratio of internal and external sodium ions across the membrane.

This fact tells that certain ions in addition to sodium ions may contribute to produce the action potential in these media or that the process except for the entry of external sodium ions is probably a cause for producing the action potentials. From this, the process for producing the action potentials in $\mathrm{Ca}$ free medium is independent of the external sodium concentration and is dependent of the membrane potential.

Next, the effect of the internal sodium concentration upon the spike height of the action potential produced has been examined. The internal sodium concentration is increased by soaking in Ca free EDTA Ringer for 24 hours. In this observation, the maximum spike height did not alter with the various concentrations of internal sodium as shown in Figure 3, C.

Conclusively, it can be said that the external or internal sodium ions in concentration affect the spike height of the action potential thus produced in these conditions less than that in Ringer.

B. Effect of external sodium upon the spike height in $30 \mathrm{mM} \mathrm{K}$ :

The resting potential reduced to about $30 \mathrm{mV}$ in $30 \mathrm{mM} \mathrm{K}$ Ringer shows the action potential by anodal polarization. When the concentration of the external sodium is changed in $30 \mathrm{mM} \mathrm{K}$ Ringer, the spike height does not alter in sodium concentration from $112 \mathrm{mM}$ to $30 \mathrm{mM} \mathrm{Na}$.

However, in detail, the maximum height of the action potential in $\mathrm{Ca}$ free EDTA Ringer is slightly (about $5 \mathrm{mV}$ ) larger than in $\mathrm{K}$ rich Ringer. This fact can show that $\mathrm{Ca}$ free depolarization and $\mathrm{K}$ rich depolarization is not strictly the same even if both show the same value of resting potential.

C. External $\mathrm{K}$ concentration upon the spike height:

At the fixed level of sodium concentration at 20 or $50 \mathrm{mM} \mathrm{Na}$ (Figure 3, B), the change of external $\mathrm{K}$ concentration does not affect the spike height of action potentials. This result is not in agreement with the statement of Lüttgau that 
the height of action potential is linearly dependent on the logarithm of the external $\mathrm{K}$ concentration in high $\mathrm{K}$ medium (11).

It may be said that the ions responsible for the generation of the action potential or active depolarization are not only sodium ions. In summary, it is worthwhile to clarify that the membrane is capable of producing the action potentials when a large amount of the permeable ions are present outside the membrane. Koketsu (12) described that the external sodium is dispensable and membrane property is more essential for the generation of action potential. The present data strongly support this conception.

D. Anodal break response and hyperpolarizing response:

Both responses can be seen in Ca free EDTA Ringer or in $\mathrm{K}$ rich Ringer, especially in the latter case. In general, the anodal break response preceeds the hyperpolarizing response and the continuous polarization makes it easier to generate these responses.

\section{DISCUSSION}

Why the resting potential drops in $\mathrm{Ca}$ free Ringer or in $\mathrm{K}$ rich Ringer is the main problem in the present experiments. Huxley (13) said that the reduction of resting potential due to $\mathrm{Ca}$ deficiency is caused by an increase in $\mathrm{K}$ permeability. Frankenhaeuser and Hodgkin (14) found out that the squid axon becomes totally inexcitable in $\mathrm{Ca}$ free solution. The author, however, is able to obtain the action potential even when the total external $\mathrm{Ca}$ has been removed in the sartorius of frogs. The action potential thus produced is not pathological in shape or height. More or less prolongation and non-obligation to the all or none law are the points different from the normal action potential. Conclusively, the action potential of muscle membrane appears in the medium without external $\mathrm{Ca}$ ions; i. e. no $\mathrm{Ca}$ ions are necessary for producing action potentials. In other words, the entry of $\mathrm{Ca}$ ions for the active depolarization is not necessary.

Assuming that the spike height of the action potential is not determined by the external $\mathrm{Na}$ concentration but by the total amount of the exchangeable ions, the spike height of action potentials in Ringer, in Ca free EDTA Ringer, or in $\mathrm{K}$ rich Ringer in isotonic condition should be equal. Experimentally, the spike in Ca free EDTA Ringer is similar to that in Ringer, but that in $\mathrm{K}$ rich Ringer is lower than that in another solution. This must be explained by the slight difference in the membrane permeability especially to $\mathrm{K}$ ions.

It is clear from the results that the contents of $\mathrm{K}$ within muscles have no immediate relation to the level of depolarization; namely, only the increase or the decrease in $[\mathrm{K}]_{\mathbf{l}}$ is not indicative of membrane depolarization. Evidently, $[\mathrm{Na}\rfloor \mathrm{o}$ or $[\mathrm{Na}]_{i}$ has no significant correlation with the resting potential level. Summarily, only the concentration of $\mathrm{K}$ ions externally applied has a close relation with the resting potential level. This fact shows that the concentration difference of $\mathrm{K}$ ions across the membrane has no meaning in reference to the membrane potential.

What the actual change is in the depolarized membrane is the next problem. Harris (15) has an opinion that the maximum potential measured within the cell will be equal to the sum of the outer Donnan potential difference and the inner $\mathrm{K}$ concentration cell potential difference. If the two types of depolarization described 
in this resport can be explained by the membrane model proposed by Harris (15), this model should interpret the difference of the internal $\mathrm{K}$ contents in these conditions which is the most important discrepancy. The author also supposes that the ion selectivity in the normal membrane is explainable in terms of the adsorpton of cations on the surface of the membrane, and in Ringer $\mathrm{K}$ ions are more preferably situated on the anionic site of this adsorption membrane than other ions in the medium. From this, it can be understood that the number of the adsorption sites for $\mathrm{K}$ ions on the membrane surface has increased in $\mathrm{K}$ rich Ringer but has decreased in $\mathrm{Ca}$ free Ringer. At this time the competition of $\mathrm{K}$ ions with other ions at these sites should be considered.

Increase in $\mathrm{K}^{42}$ outflux in $\mathrm{K}$ rich or $\mathrm{Ca}$ free media is continuous as long as the membrane depolarization is present. In the previous report by the author et al. (16) the increase of the Ca outflux, which was observed in the $\mathrm{K}$ rich or $\mathrm{Ca}$ free condition, was considered as a possible important cause of the membrane depolarization in these cases. However, this change was always transient. At this time, it is supposed that continuous change means the presence of sustained changes in membrane property by which the modification of the diffusion of ions can take place and that transient change means the occurence of the trigger process for forced change in the membrane structure. Moreover, transient changes are the surface phenomena of the membrane, while continuous change is followed by changes in the deeper layer of the membrane. From these reasons, continuous change in $\mathrm{K}$ ion movement and the consequent change in the distribution of $\mathrm{K}$ ions are probably the results of the permeability change after the depolarization. The permeability of $\mathrm{K}$ ions is strongly influenced by the membrane potential. Accordingly, the value of the membrane potential which is maintained either naturally or artificially may be the most essential factor for the membrane behaviour. In the experimental results of the value of the membrane potential or the ionic concentration inside the membrane, the non-parallelity of the potential with the internal $\mathrm{K}$ concentration can be seen, in detail; both $\mathrm{Ca}$ free condition and $10 \mathrm{mM} \mathrm{K}$ Ringer condition cause membrane depolarization in the same degree, but the behaviour of $\mathrm{K}$ ions in both cases is different. From this, it is supposed that the membrane potential is not a reflection of $\mathrm{K}$ ions outside and inside the membrane but is a cause for the change of the distribution of $\mathrm{K}$ ions across the membrane. Because it is assumed that the cell in the steady state is neither gaining nor losing $\mathrm{K}$ and the movement of $\mathrm{K}$ is passive, the outward movement of $\mathrm{K}$ is presumably the final appearance of the membrane to maintain the homeostasis of the cell.

The conclusion has been reached that the potential difference is at least the reflection of the membrane structure which simultaneously controls the distribution of $\mathrm{K}$ ions across the membrane. The membrane structure relating to these changes can be explained by the physico-chemical state of the membrane lipoprotein. $\mathrm{Ca}$ free or high $\mathrm{K}$ medium may change the molecular configuration of the membrane lipoprotein. Both conditions will result in a similar final state of the membrane via the respective molecular reactions.

Now, one example will be given for understanding the role of ions in the membrane potentials. As is clear from $\mathrm{T}$ able 2 , the resting potential seems to be free from the ionic distribution. This suggests that the potential difference is not an immediate reflection of the distribution of $\mathrm{K}$ ions across the membrane or that only 
the composition and the movements of $\mathrm{K}$ ions are not a reliable indicator of the resting membrane potential. At this time, if there is no direct contribution of $[\mathrm{K}]_{\mathrm{i}}$ to the resting potential level, the second question whether it is possible for the chloride ion to establish certain parts of the resting potential arises. But, from the value described in this Table, the contribution of the chloride ion on the resting potential must be negligible.

In these cases, procedures probably bring forth the resulting change in the membrane structure, namely, occurence of accelerated $\mathrm{K}-\mathrm{K}$ exchange in high $\mathrm{K}$ media, and causation of slightly accelerated $\mathrm{K}-\mathrm{K}$ exchange, the net loss of $\mathrm{K}$ contents and the gain of sodium ions in $\mathrm{Ca}$ free media. But the final situation is almost the same in both cases because the membrane depolarization is in the same degree. Accordingly, it can be said that the process to generate the membrane depolarization is different in $\mathrm{K}$ rich and $\mathrm{Ca}$ free media.

TABLE 2

\begin{tabular}{l|c|c|c}
\hline & Resting potential & {$[\mathrm{K}]_{\mathbf{i}}$} & {$[\mathrm{Na}]_{\mathbf{i}}$} \\
\hline sucrose Ringer & $75 \mathrm{mV}$ & $116 \mathrm{mM}$ & $8 \mathrm{mM}$ \\
pure sucrose & 88 & 53 & 8 \\
sucrose $\mathrm{SO}_{4}$ Ringer & 81 & 117 & 9 \\
\hline
\end{tabular}

20 hrs. soaking.

If the membrane could act as ion exchanger shifting the adsorption equilibrium for $\mathrm{Na}, \mathrm{K}$, and $\mathrm{Ca}$ or if $\mathrm{K}$ behaves as Donnan equilibration in the surface of the membrane and as diffusion in the deeper layer (15), first the high $\mathrm{K}$ condition would change the surface configuration while the free condition of $\mathrm{Ca}$ would change the structure in the deeper layer. Assuming that the introduced $\mathrm{Ca}$ exchange reaction is responsible for regulating the value of the membrane potential (16), the e.m.f. would be directly determined by the difference of free energy of interaction between $\mathrm{Ca}$ or $\mathrm{K}$ and the fixed negative charge in the membrane.

The Mullins's report (17) that divalent cations penetrate at rates much slower than the alkali cations do may explain the difference in the rapidness in $\mathrm{K}$ rich and $\mathrm{Ca}$ free depolarization. Moreover, there is the possibility that $\mathrm{K}$ competes with $\mathrm{Ca}$ for the membrane structure (18). So, it is possible for the change of the membrane structure caused by $\mathrm{K}$ rich medium to be different from that by $\mathrm{Ca}$ free medium.

From the ionic conception, depolarization has been explained by increased $\mathrm{Na}$ permeability (Ca deficient) or decreased $\mathrm{K}$ permeability ( $\mathrm{K}$ rich). But the data presented here disclose that the acceleration of $\mathrm{K}$ permeability is presumed to be the end product by the change in membrane structure due to these media.

Generally, it is said that the muscle fibers display a rise in the permeability of the membrane to $\mathrm{K}$ ions when the membrane potential difference is lowered. It is apparent that the level of the membrane potential is the cause for membrane permeability. This also suggests that the muscle fiber membrane depolarized to 
the same level has the same permeability to ions. The present experimental results show that the change of the muscle membrane resistance is linear to the change of the membrane potential level and that this correlation has no relation with the cause by which the depolarization has been brought about. This shows that the same depolarization level has the same permeability in the end state; however, it does not indicate that the same molecular configuration is present.

Koketsu et al. (16) have stated that the membrane property is more essential for the membrane electrical phenomena than the movements of certain ions. In the present report too, it is evident that the change in the resting potential is the final appearance of the change in the molecular membrane architecture. The experimental results on the production of the action potentials in these depolarized conditions indicate that the condition of the membrane to produce the action potentials is determined by the molecular structure of its membrane and the spike height is controlled by the total amount of the movable ions across the membrane. The fact that the sodium ion is most readily available for the action potential is obtained only in Ringer by the phylogenesis of experimental animals. In some conditions, the membrane does not discriminate perfectly between $\mathrm{K}$ and $\mathrm{Na}$. From this it can be supposed that the important role of the total amount of ions is specially for the action potentials.

As is stated by Teorell (19) the driving force for the transport consists of the force arising from ion concentration difference and the force created by the presence of the electrical potential difference. As is clear from the results, when this concept is applied to the flux of ions in $\mathrm{K}$ rich and $\mathrm{Ca}$ free solution it is supposed that the electric field is more important than the concentration gradient. And the former may be a function of the membrane structure. Stephenson (20) described that the maintenance of the membrane potential in the experimental muscle is independent of the outward diffusion of $\mathrm{K}$. In the present experiment, the efflux of $\mathrm{K}$ ions and the subsequent change in $\mathrm{K}$ contents in the muscle do not connect directly with the value of the resting potential. But the externally applied $\mathrm{K}$ ions give the results expectable from Nernst equation. This leads to the conception that the external surface of the membrane has the site to adsorb $\mathrm{K}$ ions which is closely related to the membrane potential. Horowicz (21) has described that the forces which restrain the ionic movements are imposed both by membrane resistance and electrical potential difference across the membrane. But the present author supposes that all these phenomena are only part of the multiple expression of the membrane structure. The physical phenomena of the membrane which can be experimentally observed are probably the result of the chemical reactions in the membrane.

\section{SUMMARY}

The reduction of membrane potential of frog sartorius muscle fibers which was produced by the removal of $\mathrm{Ca}$ ions has been compared with the depolarization due to high $\mathrm{K}$. The change of membrane potential and the passive fluxes of $\mathrm{K}$ ions have primarily been investigated. At the same level of depolarization, $\mathrm{K}$ rich or $\mathrm{Ca}$ free condition has each pattern of the movements of $\mathrm{K}$ ions. This discrepancy can probably be explained by the difference in the membrane structure resulting from the high $\mathrm{K}$ or $\mathrm{Ca}$ free condition. 
Although it is said that $\mathrm{K}$ ions act on the membrane as ionic activity and $\mathrm{Ca}$ ions as the regulator of the normal structure of the cell membrane, both are the constituents which maintain the membrane structure in the respective ways. However, the valency of each ion may be the most important factor for the membrane structure by which the resting or action potential can be produced.

\section{REFERENCES}

1. Toвias, J.H. : Injury and membrane potentials in frog muscle after depleting potassium and producing other changes by soaking in potassium-free salt solution or distilled water. J. cell. comp. Physiol. 36, 1-13, 1950.

2. Grundfest, H., C. Y. Kao and M. Altamirano: Bioelectric effects of ions microinjected into the giant axon of Loligo. J. gen. Physiol. 38, 245-282, 1954.

3. Shaw, F. H. , S. E. Simon and B. M. Johnstone: The non-correlation of bioelectric potentials with ionic gradients. J. gen. Physiol. 40, 1-17, 1956.

4. Koketsu, K. and Y. Kimura: The resting potential and intracellular potassium of skeletal muscle in frog. J. cell. comp. Physiol. 55, 239-244, 1960.

5. Ling,G. N. : The interpretation of selective ionic permeability and cellular potentials in terms of the fixed charge-induction hypothesis. J.gen. Physiol. 43, 149-174, 1960 .

6. Adrian, R.H. : The effect of internal and external potassium concentration on the membrane potential of frog muscles. J. Physiol. 133, 631-658, 1956.

7. Koketsu, K. and S. Nishi : Restoration of neuromuscular transmission in sodium-free hydrazinium solutions. J. Physiol. 14\%, 239-252, 1959.

8. KoKetsu, K. andK. Noda : Restoration of membrane excitability of calcium-deficient muscles by anodal polarization. Nature. 18\%, 243-244, 1960.

9. Koketsu, K. and K. Noda: Membrane responses of frog skeletal muscle fibers in calcium-free media. J. cell. comp. Physiol. 59, 323-332, 1962.

10. Frankenhaeuser, B. : Steady state inactivation of sodium permeability in myelinated nerve fibers of Xenopus laevis. J. Physiol. 148, 671-676, 1959.

11. LÜтtgaU, H.C. : Das Kalium-Transportsystem am Ranvier-Knoten isolierter markhaltiger Nervenfasern. Pflügers Archiv. 2\%1, 613-633, 1960.

12. Koketsu, K. : Mechanism of active depolarization. AAAS. 1961.

13. Huxley, A.F. : Ion movements during nerve activity. Ann. N. Y. Academy of Science. $81,1958$.

14. Frankenhaeuser, B. and A. L. Hodgkin. : The action of calcium on the electrical properties of squid axons. J. Physiol. 197, 218-244, 1957.

15. Harris, E. J. : Transport and Accumulation in biological system. Academic Press, New York. 1960.

16. Noda, K., K. Koketsu, and S. Miуamoto, : Release of membrane calcium and membrane depolarizattion in frog nerve. Fed. Proc. \&0., 346, 1961.

17. Moluins, L. J. : The penetration of some cations into muscle. J. gen. Physiol. $\angle \mathscr{Q}$, 817-829, 1959.

18. Sснмірт, H. : Die Wirkung von Calcium Ionen auf das Membranpotential markhaltiger Nervenfasern. Pflügers Archiv. 2r1, 634-654, 1960.

19. Teorel, T. : Electrokinetic membrane processes in relation to properties of excitable tissue. J. gen. Physiol. 42, 831-845, 1959.

20. Stephenson, W. K. : Membrane potential changes and ion movements in the frog sartorius muscle. J. cell. comp. Physiol. 50, 105-128, 1957.

21. Horowicz, P. : Influence of ions on the membrane potential. AAAS. 1961. 